\title{
Os Consórcios públicos como vias de implementação da Política Nacional de Resíduos Sólidos (PNRS)
}

\section{Public Consortia as waysofimplementingtheNationalPolicyonSolidWaste}

\author{
Yasmin da Silva Onofre ${ }^{1}$ \\ Marlene de Paula Pereira ${ }^{2}$ \\ Maria Izabel Vieira Botelho ${ }^{3}$
}

\section{Resumo}

A Lei Política Nacional de Resíduos Sólidos (Lei o 12.305), sancionada em02 de agosto de 2010, apresenta-se como um instrumento normativo para orientar os municípios quanto à gestão ambientalmente adequada e integrada dos resíduos sólidos. Essa lei propõe que sejam consideradas as variáveis ambiental, social, cultural, econômica, tecnológica e de saúde pública, através de uma visão sistêmica. Além disso, reconhece o resíduo sólido reutilizável e reciclável como um bem econômico e de valor social, gerador de trabalho e renda e promotor de cidadania. De acordo com o artigo 30, V, da CF, compete aos municípios organizar e prestar os serviços públicos de interesse local. Assim, a partir da Lei o 12.305/2010, tornou-se obrigação legal dos municípioselaborar os planos de resíduos sólidos, implantar a coleta seletiva e os sistemas de logística reversa, além de incentivar a criação e o desenvolvimento de cooperativas ou de outras formas de associação de catadores de materiais reutilizáveis ou recicláveis e de conselhos de meio ambiente, etc.

\footnotetext{
Abstract

${ }^{1}$ Aluna do curso de Gestão Ambiental do IF Sudeste MG, Campus Barbacena, pesquisadora bolsista do CNPQ. E-mail: yasmin_pjrs@yahoo.com.br

2. Doutoranda em Extensão Rural no Departamento de Economia Rural da UFV, professora de Direito do IF Sudeste MG, Campus Barbacena. E-mail: depaulamarlene@yahoo.com.br

${ }^{3}$ Pós-doutora em Sociologia do Desenvolvimento Rural pela Universidade de Wageningen, Holanda. Doutora em Sociologia pela Universidade Estadual Paulista Júlio de Mesquita Filho. Atualmente é Professora Associada da Universidade Federal de Viçosa, MG. E-mail: mbotelho@ufv.br
} 
The NationalSolidWastePolicyAct( Law No. 12,305 )culminating in02 August 2010 , presentsitself as a legal instrumenttoguidemunicipalitiesbyenvironmentallyappropriateandintegratedsolid waste management. Thisbillproposesthattheenvironmental, social, cultural, economic, technologicalandpublichealthvariables are considered, through a systemicview. Furthermore, it recognizesthesolidreusableandrecyclablewaste as aneconomicand social value as well, generatingjobsandincomeand promoter ofcitizenship. AccordingtoArticle30, V oftheConstitution, it is for municipalitiesto design anddeliverpublicservicesof local interest. Thus ,fromthe Law 12.305/2010 became legal obligationofmunicípioselaborarplanssolidwaste , deployingselectivecollectionand reverse logistics systems, andencouragethe establishment anddevelopmentofcooperativesorotherformsofassociationpickersofrecyclableorr eusablematerialsandenvironmentalcouncils, etc.

PALAVRAS CHAVES: Coleta Seletiva, Serviços Públicos, reciclagem.

KEYWORDS: Selectivecollection, Publicservices, recycling.

\section{Considerações Iniciais}

A Lei Política Nacional de Resíduos Sólidos (Lei no 12.305), sancionada em 02 de agosto de 2010, apresenta-se como um instrumento normativo para orientar os municípios quanto à gestão ambientalmente adequada e integrada dos resíduos sólidos.

Essa lei propõe que sejam consideradas as variáveis ambiental, social, cultural, econômica, tecnológica e de saúde pública, através de uma visão sistêmica. Além disso, reconhece o resíduo sólido reutilizável e reciclável como um bem econômico e de valor social, gerador de trabalho e renda e promotor de cidadania.

De acordo com o artigo 30, V, da CF, compete aos municípios organizar e prestar os serviços públicos de interesse local. Assim, a partir da Lei no 
12.305/2010, tornou-se obrigação legal dos municípios elaborar os planos de resíduos sólidos, implantar a coleta seletiva e os sistemas de logística reversa, além de incentivar a criação e o desenvolvimento de cooperativas ou de outras formas de associação de catadores de materiais reutilizáveis ou recicláveis e de conselhos de meio ambiente, etc.

Uma pesquisa de campo realizada na região dos Campos das Vertentes, em Minas Gerais, envolvendo os municípios de Barbacena, Antônio Carlos, Ibertioga, Juiz de Fora e Santos Dumont, revelou o que já era esperado: os municípios de pequeno porte não estão sendo capazes de cumprir a Lei da Política Nacional de Resíduos Sólidos, isto é, de implementar as medidas necessárias para gerenciamento do resíduo sólido, tais como eliminação dos lixões. O prazo para que tais medidas sejam postas em prática, de acordo com a lei, é até 2014, mas dificuldades financeiras e administrativas enfrentadas pelos municípios tem impedido que as ações saiam do papel.

Diante desse problema, o presente artigo tem o objetivo de apresentar uma reflexão a respeito dosconsórcios públicos. Acredita-se que, para os municípios pequenos, que representam a maioria dos municípios brasileiros, essa pode ser uma via que possibilitará a implementação da PNRS.

\section{A Política Nacional de Resíduos Sólidos}

A preocupação acerca da gestão dos resíduos sólidos no mundo teve início a partir da década de 70, quando deu-se início à discussões acerca do impacto das atividades humanas sobre o planeta e suas conseqüências. A partir daí, a principal preocupação dos países desenvolvidos, segundo Demajorovic (1996), "caracterizou-se pela disposição dos resíduos".

Essa percepção acarretou na eliminação da maioria dos lixões a céu aberto dos países pertencentes à Organização para Cooperação e Desenvolvimento Econômico, que buscaram alternativas para a disposição final em aterros sanitários ou a utilização de incineradores. Mesmo estas técnicas apresentavam resultados nocivos ao meio ambiente, tais como emissão de compostos químicos na atmosfera e contaminação de lençóis freáticos, o que 
levou tais países a priorizarem a redução, reutilização e reciclagem dos resíduos nas décadas de 80 e 90.

No Brasil, as discussões acerca da gestão de resíduos sólidos tiveram início formalmente no ano de 1989, com o envio pelo Senado Federal à Câmara dos Deputados do Projeto de Lei (PL) n 354 , dispondo sobre "o acondicionamento, a coleta, o tratamento, o transporte e a destinação final dos resíduos de serviços de saúde". Já na Câmara dos Deputados, a discussão teve início a partir do $\mathrm{PL} \mathrm{n}^{\circ}$ 203, dispondo sobre a pauta encaminhada pelo Senado. As informações que se seguem foram obtidas com base disponíveis nos sítios do Senado e Câmara dos Deputados.

A partir do recebimento do $P L \mathrm{n}=354$, que se tornara a $P L n^{\circ}=203$, diversos outros projetos onde as temáticas eram consideradas pertinentes foram sendo incluídos ao projeto original. Então, a mesa diretora da Câmara encaminhou ainda no ano de 1991 a proposta para análise interna pelas Comissões de Seguridade Social e Família (CSSF) e pela Comissão de Defesa do Consumidor, Meio Ambiente e Minorias (CDCMAM) e pela Comissão de Constituição, Justiça e Cidadania (CCJC) do Senado Federal. No ano de 1999 houve terceiro despacho da mesa diretora do projeto com novas propostas incluídas para as mesmas Comissões mencionadas, adicionando-se o despacho também para a Comissão de Desenvolvimento Urbano e Interior (CDUI).

No ano de 2001 instituiu-se a Comissão Especial da Política Nacional de Resíduos na Câmara com o objetivo de analisar o PL 203/91, juntamente com mais de 70 projetos a ele já apensados.

Já no ano de 2007 o Ministério do Meio Ambiente, em articulação com demais entidades, órgãos e Ministérios elaborou uma proposta, o Projeto de Lei № 1991/2007, que foi encaminhada à Câmara dos Deputados. O Projeto compreendia o disposto no PL no 203/1992 e as demais inclusões de propostas já efetivadas, e dispunha sobre a "Política Nacional de Resíduos Sólidos" em compatibilidade com a Lei ㄲo. 11.445/07 (Política Nacional de Saneamento 
Básico) e com a Lei №. 11.795/08 (Lei do Consórcio), que esteve em trâmite nos anos de 2006 a 2008.

No ano de 2008 foi instituído pela Mesa Diretora da Câmara dos Deputados o Grupo de Trabalho de Resíduos, para examinar o parecer da Comissão Especial com relação ao PL № 203/91. As discussões ocorridas no Grupo de Trabalho levaram a realização de audiências públicas, reuniões junto à setores envolvidos a fim de complementar a proposta. Em 2009, foi então apresentada pelo Grupo a "Minuta de Subemenda Substitutiva Global de Plenário ao PL 203/1991 e seus apensos", que representava o relatório do Grupo e que levava em conta o exposto nas discussões junto à sociedade. Após emissão de um último parecer da Comissão Especial, houve votação no Congresso e a proposta foi aprovada, sendo posteriormente encaminhada ao Senado Federal.

A partir daí, a proposta da Lei da Política Nacional de Resíduos Sólidos seguiu para aprovação da Presidência da República, que ocorreu em 02 de Agosto de 2010, quando foi sancionada sem propostas de veto.

A proposta da Lei levou em consideração as Conferências Nacionais de Meio Ambiente, as discussões dos Fóruns Lixo e Cidadania, as reivindicações dos catadores de materiais recicláveis assim como a opinião de diversos outros setores relacionados. Por isso, a proposta final sancionada pela Presidência é uma legislação complexa e robusta, prevendo instrumentos importantes para sua concretização, como a responsabilidade compartilhada, os planos de resíduos sólidos, a coleta seletiva, a logística reversa entre muitos outros, e interliga todos os entes, federados ou não, que se relacionam com a temática.

Para a consecução dos objetivos contidos na PNRS os municípios tem papel fundamental levando-se em conta que possuem a titularidade dos serviços de limpeza urbana e manejo dos resíduos sólidos. Porém, há muitas dificuldades administrativas e financeiras a serem enfrentadas pelos municípios de nosso país para que tal gestão atenda ao previsto na legislação em questão. É o que se passa a discutir. 


\section{Os desafios para implementação da PNRS}

Observando-se a estrutura do sistema de repartição de competências trazido pela Constituição de 1988 percebe-se que o constituinte buscou o equilíbrio das relações entre o poder central e os poderes estaduais e municipais. Para fazer isto teve que superar o modelo antigo em que as competências eram rigidamente distribuídas, mediante critérios que definiam o âmbito de atuação exclusiva de cada entidade estatal, para acolher formas de composição mais complexas em que cada ente continua possuindo competências exclusivas e privativas, porém, conjugadas com competências comuns ou concorrentes, que podem ser compartilhadas pelas entidades estatais (BARROSO, 2007:3).

Essa mudança de comportamento por parte dos constituintes no sentido de admitir que mais de um ente federativo seja competente para legislar/atuar acerca de determinada matéria deve-se muito à dificuldade para solucionar os problemas, cada vez mais complexos, em uma única esfera de poder.

Segundo BARROSO (2007) o interesse local é um conceito dinâmico, ou seja, aquilo que hoje é considerado de interesse absolutamente local, com a passagem do tempo poderá passar para a esfera de interesse regional e até mesmo federal. Vários fatores podem causar esta alteração como a fusão de municípios limítrofes ou mesmo a necessidade de uma ação integrada para melhor alcançar o interesse público.

Porém, há situações em que em vez de predominar o interesse local, predomina o interesse comum de um conjunto de Municípios, de uma região mais ampla do que um Município isolado.

O conceito de interesse local deve ser aferido diante do caso concreto. Cabe ressalvar que não se trata de interesse exclusivo do Município; nem de interesse privativo da localidade; nem de interesse único dos munícipes. Se 
fosse exigida essa exclusividade, bem reduzido ficaria o âmbito da administração local, aniquilando-se a autonomia prevista pela Constituição. Mesmo porque não há interesse municipal que não o seja reflexamente da União e do Estado-Membro, como também não há interesse regional ou nacional, que não ressoe nos Municípios, como partes integrantes da Federação brasileira, através dos Estados a que pertencem.

Nesse sentido, o art. 23 da Constituição Federal foi acrescido de um expressivo parágrafo que trata de possibilidade de cooperação entre a União e os Estados, o Distrito Federal e os Municípios, tendo em vista o equilíbrio do desenvolvimento e do bem estar em âmbito nacional.

As vantagens de haver cooperação entre os entes são muitas. As pessoas políticas poderiam realizar troca de informações, ações conjuntas e ampliar a fiscalização. A LPNRS traz de modo expresso a possibilidade de convênios e consórcios municipais para a realização do gerenciamento dos resíduos sólidos.

Após a promulgação da Constituição de 1988, ocorreu um aumento das receitas de transferência das instâncias federal e estadual para os Municípios, conferindo-Ihe maior aporte de recursos sem vinculação determinada, o que possibilitaria a implementação dos projetos de 'interesse local' (SANTOS, 2009). Os municípios experimentaram ainda maior fortalecimento institucional ao passar a ter competência pela administração de seus tributos (MATTOS E SANTOS, 2008: 78).

Entretanto, o aumento das responsabilidades assumidas pelos Municípios em face da diminuição dos gastos federais não foi acompanhada de uma planejada redistribuição de encargos a partir dos governos federal e estaduais para os municipais. A transferência de crescentes responsabilidades aos governos municipais passou a ser percebida como "municipalização" das políticas, em particular das políticas sociais (SANTOS , 2009).

A partir de 1995, a União passa a colocar em xeque a autonomia financeira municipal por meio de uma série de emendas constitucionais que 
aumentaram as receitas federais sem que os municípios pudessem se beneficiar do aumento do peso da carga tributária, que passou a crescer devido ao aumento das receitas não-partilháveis com os entes subnacionais, fato que limitou as receitas dos municípios (SANTOS , 2009).

A partir de 1995, portanto, a descentralização e o fortalecimento institucional dos entes subnacionais foram sendo revertidos. A União passou a aumentar seu controle sobre a formulação das políticas públicas, ainda que a execução continuasse a ser responsabilidade dos governos regionais e locais (MATTOS E SANTOS, 2008: 78).

O movimento de descentralização no Brasil foi muito marcado pela tentativa de transferir encargos e responsabilidades do governo central para os municípios e tal transferência não foi acompanhada pela preparação e fortalecimento dos municípios e dos agentes locais (SOUZA, 2006: 375).

Segundo SOUZA (2006: 375), a lógica que rege a distribuição de competências entre os entes constitutivos da Federação é paradoxal. Por um lado, os constituintes decidiram reduzir os recursos financeiros federais via-àvis aos outros dois níveis de governo (situação que foi revertida ao longo dos últimos anos), por outro, aumentaram as competências legislativas e de jurisdição do governo federal ao mesmo tempo em que aumentavam o leque das competências concorrentes sem a adoção de mecanismos mais abrangentes de relações intergovernamentais.

Considerando-se o Estado de Minas Gerais, em especial a região do Campo das Vertentes, pode-se afirmar, a partir de dados do IBGE, que a maior parte dos municípios é constituída de pequenas cidades, de base econômica dependente das atividades agropecuárias de alcance local, incapazes de serem financeiramente autônomas e, portanto, incapazes de experimentar a descentralização como um fortalecimento de seu papel institucional na Federação.

Esses pequenos municípios, na verdade, experimentam a desconcentração das políticas que a União definiu como sendo de alcance 
nacional e para as quais criou fundos que viabilizam a sua execução, como são os casos da educação e da saúde. Tais municípios se ressentem, ademais, até de capacidade técnica para executar bem as políticas (SANTOS, 2009).

Com o orçamento praticamente todo comprometido com os investimentos nas áreas da saúde, educação e pagamento de pessoal, a maior parte dos municípios brasileiros pouco realizam nas áreas urbanística e ambiental.

De com dados da pesquisa MUNIC, realizada pelo IBGE, em 2008, $54,8 \%$ dos municípios dispõem de secretaria municipal em conjunto com outros temas. Outros $28,9 \%$ dos municípios possuem departamento, assessoria, setor ou órgão similar ligado ao tema. E somente $16,3 \%$ contam com secretaria exclusiva (IBGE, 2008). A secretaria exclusiva é observada quase somente em municípios populosos.

Com relação aos recursos específicos para a área de meio ambiente, que são fundamentais para viabilizar qualquer ação da prefeitura na área ambiental, menos da metade das prefeituras $(37,4 \%)$ dispõe de tais recursos. Assim, entre os municípios com até 5000 habitantes, 29,6\% têm recursos específicos para a área ambiental. Esse percentual se eleva para 97,3\% entre os municípios com mais de 500000 habitantes (IBGE, 2008).

De acordo com dados disponíveis no sitio da Secretaria da Fazenda, dentre as principais transferências da União destacam-se: o Fundo de Participação dos Estados e do Distrito Federal (FPE); o Fundo de Participação dos Municípios (FPM); o Fundo de Compensação pela Exportação de Produtos Industrializados (FPEX); o Fundo de Manutenção e Desenvolvimento da Educação Básica e de Valorização dos Profissionais da Educação (Fundeb); e - Imposto sobre a Propriedade Territorial Rural (ITR). (http://www3.tesouro.fazenda.gov.br/estados municipios/transferencias constit ucionais.asp).

As transferências dos estados aos municípios correspondem aos repasses do Imposto sobre Operações relativas à Circulação de Mercadorias e 
sobre a Prestação de Serviços de Transporte Interestadual e Intermunicipal e de Comunicação (ICMS), do Imposto sobre a Propriedade de Veículos Automotores (IPVA) e do Imposto sobre Produtos Industrializados (IPI). Além dos repasses dos demais entes através dos fundos, os municípios podem arrecadar os seguintes impostos de sua competência: Imposto sobre a propriedade predial e territorial urbana (IPTU), Imposto sobre as transmissões de bens imóveis (ITBI), Imposto sobre serviços de qualquer natureza (ISS), entre outros. Tais tributos municipais arrecadados, juntamente com as transferências executadas pelos estados e pela união compõem essencialmente as receitas dos municípios brasileiros.

Segundo Tristão (2003), os municípios que possuem maior independência das transferências intergovernamentais contam com uma arrecadação do Imposto Predial e Territorial Urbano (IPTU) e Imposto sobre Serviços de Qualquer Natureza (ISS) elevada. Quanto à arrecadação do IPTU ressalta que:

\begin{abstract}
"Diferentemente da tendência geral, alguns municípios têm obtido bons resultados na arrecadação do IPTU. São cidades com atrativos turísticos, cujo bom desempenho tributário pode ser explicado pela existência, no local, de propriedades privadas altamente valorizadas que proporcionam uma boa base tributável (TRISTÃO, 2002)".
\end{abstract}

O autor ressalta ainda que nos municípios de pequeno porte é alto 0 índice de inadimplência dos cidadãos, o que acarreta em grandes diferenças entre os valores previstos para a arrecadação e o montante factualmente realizado.

Tristão (2003), argumenta que a limitação da base tributária de competência municipal não deve ser apontada como única responsável pelo 
mau desempenho da arrecadação, uma vez que esta base é equivalente ou maior que a encontrada em muitos países. Duas outras razões também devem ser consideradas, uma de ordem técnica e outra de ordem política. O autor explica que a razão de ordem técnica se apresenta devido á ineficiência na administração dos tributos pela gestão municipal, enquanto que a razão de ordem política relaciona-se ao envolvimento político que o aumento ou existência da cobrança dos tributos de competência do município poderia causar.

As dificuldades financeiras para desenvolvimento da autonomia dos municípios de pequeno porte para incremento de sua economia representam uma parcela do problema por estes enfrentados, porém, outro fator que devese considerar é a falta de estrutura e de capacitação do corpo técnico dos municípios brasileiros.

No que se refere às dificuldades dos municípios brasileiros em implementar a Política Nacional de Resíduos Sólidos, acredita-se que ambos os fatores apresentados contribuem para o atual quadro.

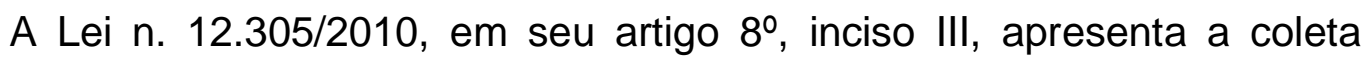
seletiva como um de seus instrumentos, devendo propiciar a integração dos catadores ao manejo dos resíduos a fim de promover a inclusão social e cidadania. Entretanto, sabe-se que a implementação de projetos desse tipo requer, fundamentalmente, corpo técnico qualificado e especializado na área da gestão de resíduos, o que também demanda recursos.

A responsabilidade compartilhada também recai sobre os municípios para a promoção de ações que minimizem o volume de resíduos sólidos gerados. Tais ações também estão condicionadas à disponibilidade de recursos financeiros e de pessoal capacitado.

A limitação de especialistas na área da gestão ambiental está expressa inclusive na elaboração pelos municípios de seus Planos de Gestão Integrada de Resíduos, previstos como instrumento da PNRS. Estes planos devem conter diagnóstico da situação da geração de resíduos, metas para a 
eliminação e recuperação de lixões entre outras, além de programas para o atendimento das metas previstas, devendo ser elaborado de forma transversa por diversos profissionais. A não elaboração resultará na restrição ao acesso de recursos da união (art.18).

A PNRS prevê que os municípios organizados em consórcios intermunicipais estejam acima na ordem de prioridade para a destinação de recursos federais. Todavia, tal organização em consórcios permeia questões de ordem política, que estão relacionadas à vontade de atuação dos gestores público frente à temática e à limitações quanto à integrações entre partidos políticos.

Diante das dificuldades acima apresentadas, fica claro que os municípios brasileiros, principalmente os de pequeno porte, estão enfrentando grandes dificuldades na gestão pública, incluindo-se a relacionada aos resíduos sólidos. Os resultados apresentados a seguir foram obtidos a partir de uma pesquisa de campo realizada com o propósito de averiguar a real situação de alguns municípios mineiros quanto à adequação de questões pontuais previstas na Política Nacional de Resíduos Sólidos. Foram escolhidos os municípios de Barbacena, Antônio Carlos, Ibertioga, Juiz de Fora e Santos Dumont. A razão da escolha deveu-se, principalmente à proximidade das localidades e semelhanças no que se refere aos aspectos sociais, ambientais e econômicos. Note-se que a seleção dos municípios envolveu um de grande porte (Juiz de Fora), um de médio porte (Barbacena) e três de pequeno porte. A metodologia utilizada foi a aplicação de questionários e realização de entrevistas estruturadas junto aos gestores da política municipal de resíduos sólidos dos municípios mencionados, tendo sido realizadas durante os meses de outubro de 2012 a maio de 2013. 

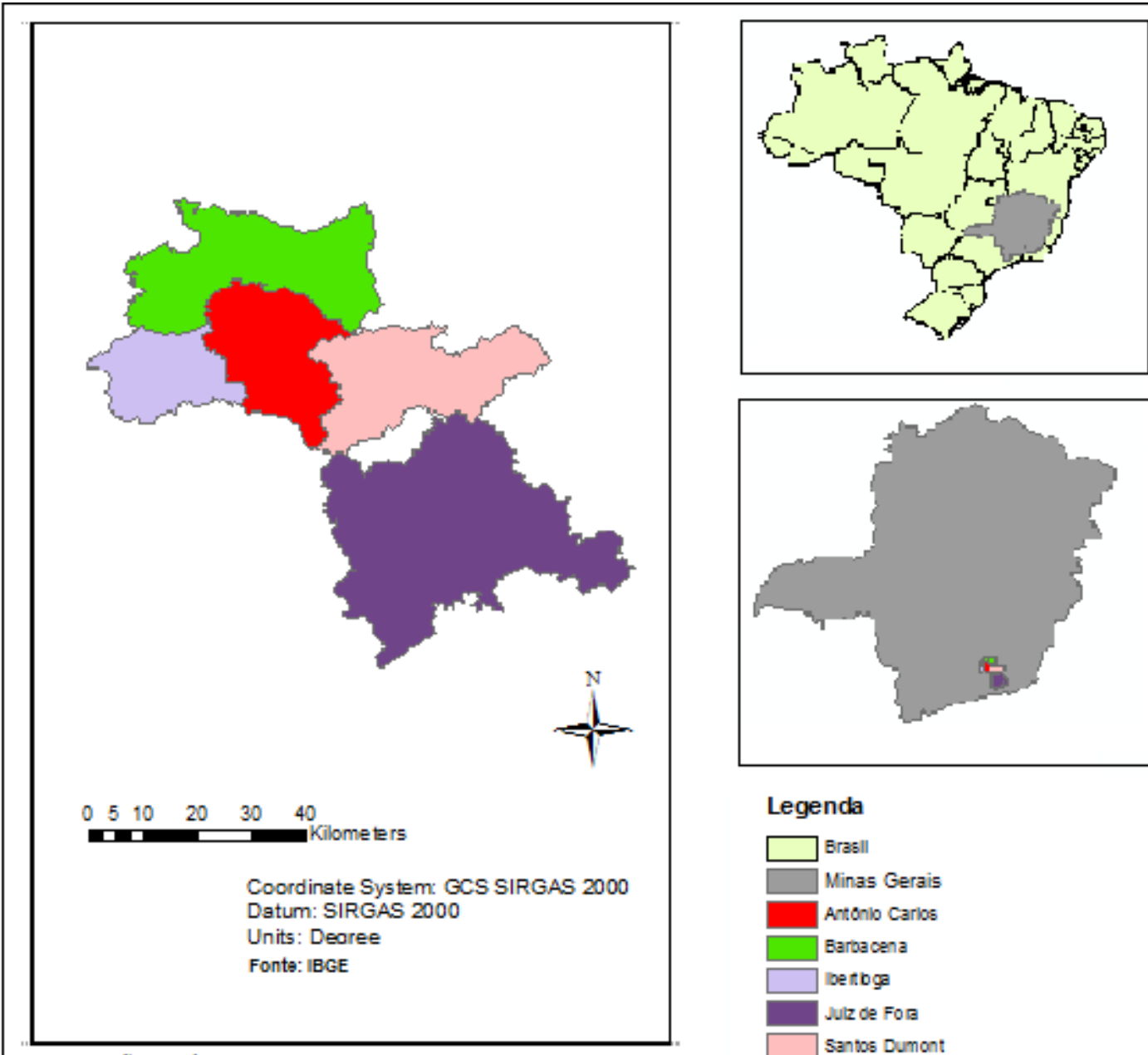

Elaboração: Natália O. Dias

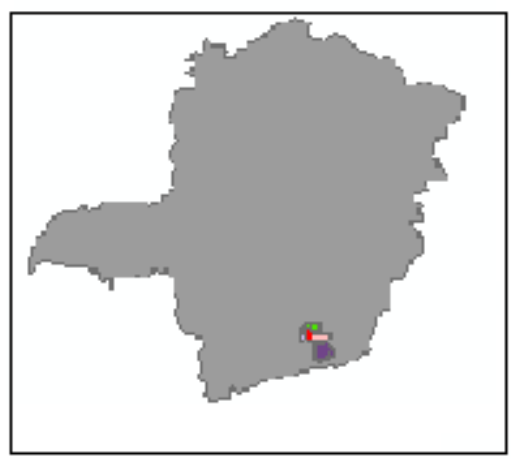

Legenda

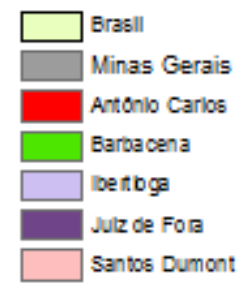

A tabela a seguir apresenta um breve panorama da produção diária de resíduos e da população de cada uma das cidades.

Tabela 1 - População em número de habitantes dos municípios estudados

\begin{tabular}{|c|c|l|}
\hline Município & \multicolumn{1}{|c|}{$\begin{array}{l}\text { Valor médio } \\
\text { habitantes (1) de }\end{array}$} & $\begin{array}{l}\text { produção de } \\
\text { de sólidos/dia } \\
\text { resíduos } \\
\left.\mathbf{(}^{2}\right)\end{array}$ \\
\hline Juiz de Fora & 516.247 habitantes & \multicolumn{1}{|c|}{$\begin{array}{l}780 \\
\text { toneladas/dia }\end{array}$} \\
\hline Barbacena & 126.284 habitantes & 60 \\
\hline
\end{tabular}




\begin{tabular}{|l|c|cc|}
\hline & & toneladas/dia & \\
\hline Santos Dumont & 46.284 habitantes & $\begin{array}{c}15 \text { a } \\
\text { toneladas/dia }\end{array}$ \\
\hline Antônio Carlos & 11.114 habitantes & $\begin{array}{c}4 \text { a } \\
\text { toneladas/dia }\end{array}$ \\
\hline Ibertioga & 5.036 habitantes & \multicolumn{2}{|c|}{800 quilos/dia } \\
\hline
\end{tabular}

${ }^{1}$ Fonte: Censo IBGE, 2010. ${ }^{2}$ Fonte: Pesquisa direta.

De acordo com a pesquisa, quatro, dos cinco municípios pesquisados são responsáveis diretamente pela prestação e execução de serviços relacionados à coleta, transporte e transbordo dos resíduos sólidos gerados, havendo somente um município, Barbacena, que faz uso da terceirização do serviço, por empresa contratada.

O município de Juiz de Fora é o único que possui aterro sanitário para a disposição final de rejeitos, com administração por empresa privada, onde há recebimento dos resíduos de diversos municípios vizinhos, incluindo-se os municípios de Barbacena e Santos Dumont. Cabe aqui ressaltar que os municípios de Barbacena e Santos Dumont possuem locais destinados à triagem dos materiais recicláveis, porém, o restante, incluindo-se os resíduos orgânicos e demais, são destinados ao aterro sanitário de Juiz de Fora. Em Antônio Carlos, há disposição dos resíduos, sem separação em aterro controlado, enquanto em Ibertioga há uma Usina de Triagem e Compostagem UTC, onde há vala para a disposição dos rejeitos.

A destinação final, compreendendo ações como a reutilização, reciclagem, compostagem, a recuperação e o aproveitamento energético ou outras destinações, ocorre nos municípios de Ibertioga, Juiz de Fora e em Santos Dumont, havendo nos dois últimos a participação de cooperativas de catadores de materiais recicláveis nos processos de reciclagem e reutilização. A Usina de Triagem e Reciclagem do município de Ibertioga realiza ainda o tratamento de seus resíduos hospitalares dentro de suas instalações, através de autoclaves, e também dos resíduos orgânicos, através do processo da compostagem. 
A PNRS considera como relevante $o$ incentivo à criação e ao desenvolvimento de cooperativas ou de outras formas de associação de catadores de materiais reutilizáveis e recicláveis para a promoção da cidadania e inclusão social dos trabalhadores do segmento. Demajorovch (2006) ressalta que a partir dos anos 90 teve início o reconhecimento dos catadores como um dos elementos centrais de programas de gestão compartilhada de resíduos sólidos.

Tal reconhecimento auxiliou o processo de estruturação da PNRS estabelecendo tais diretrizes com relação ao catador. Conforme já mencionado, os municípios de Barbacena, Santos Dumont e Juiz de Fora possuem atuação de cooperativas e associações de catadores no processo de triagem dos materiais na destinação final dos resíduos. Em lbertioga a triagem dos resíduos é feita por funcionários municipais que trabalham na UTC, sendo estes resíduos encaminhados para leilão realizado pela Fundação Estadual de Meio Ambiente - FEAM. No município de Antônio Carlos iniciativas para fomento à organização dos catadores do município em cooperativas foram promovidas, mas não obtiveram resultados favoráveis.

Observando-se a disposição final dos resíduos, os vazadouros a céu aberto (lixões) constituíram, até o ano de 2008, o destino final dos resíduos sólidos em 50,8\% dos municípios brasileiros, conforme revelou a PNSB 2008. De acordo com dados do Relatório de Progresso da Destinação de Resíduos Sólidos Urbanos em Minas Gerais (FEAM, 2011), ainda existe uma parcela expressiva da população do estado cujos resíduos são encaminhados para aterros controlados (3.049.930 hab., 18,2 \%) ou lixões (4.347.702 hab, 26,0\%). Nesse sentido, a Política Nacional prevê o término destas duas formas de disposição final até o ano de 2014, conforme dispõe o artigo 54. Todos os municípios estudados estão cientes deste prazo e afirmam estarem tomando medidas para a adequação da destinação e disposição final dos resíduos e rejeitos gerados.

Os Planos de Gestão Integrada de Resíduos Sólidos apresentam-se como importante instrumento para 0 planejamento das ações de 
gerenciamento dos resíduos. As cidades de Juiz de Fora, Barbacena e Santos Dumont e lbertioga estão em processo inicial ou de finalização do Plano. O município de Antônio Carlos que ainda não teve o processo de elaboração iniciado.

A elaboração dos Planos de Gestão Integrada compreende a análise de diversos componentes tais como sociais, ambientais, culturais de cada região e deve ser realizado por profissionais multidisciplinares. Esse fato apresenta-se, muitas vezes, como dificuldade para os municípios brasileiros, devido às limitações orçamentárias. Como alternativa a essa dificuldade, a PNRS prevê que os municípios se organizem em Consórcios Intermunicipais - CIM e, desse modo, consigam a elevação das escalas de aproveitamento e a redução de custos envolvidos em todo o processo de gestão integrada e manejo dos resíduos sólidos.

Segundo Barros (1995, p. 107), "os CIM poderão traçar prioridades políticas de intervenção, em sintonia com as políticas econômicoadministrativas do governo estadual", o que reflete claramente algumas das diversas variáveis positivas envolvidas no consorciamento.

Os municípios analisados não estão organizados em Consórcio Intermunicipal para a gestão dos resíduos sólidos, embora a disposição final dos resíduos de alguns ocorra em um aterro sanitário comum.

\section{Possibilidades de uma agenda comum: os consórcios públicos como via para implementação da PNRS}

A pesquisa realizada nos municípios da região de Campos da Vertentes evidenciou as dificuldades que os municípios de pequeno porte tem enfrentado para por em prática as determinações da LPNRS. Nesse sentido, os convênios e os consórcios apresentam-se como uma forma unir forças para cumprir o que a lei determina e, principalmente, para melhorar a qualidade de vida dos habitantes. 
Além de poder conjugar orçamentos de um grupo de municípios, a associação entre municípios permite maior eficiência na mobilização de recursos e na utilização de serviços públicos para os quais é necessária escala mínima de operações (em geral superior à população de um município pequeno).

Os problemas ambientais são, em regra, complexos, pois demandam uma série de medidas interligadas. Para que a atuação nesta seara seja realmente eficaz devem ser extrapolados os limites territoriais de municípios, estados ou até países. Logo, algum tipo de cooperação entre municípios é fundamental para que tais problemas sejam enfrentados da forma adequada.

Desde a Constituição de 1988, foram surgindo acordos intermunicipais que permitiam o funcionamento em rede na prestação de serviços, coordenando demandas e ofertas entre municípios vizinhos. Os consórcios intermunicipais difundiram-se, principalmente nas áreas da saúde e de gestão de recursos hídricos. Progressivamente foram ganhando força soluções associativas, certamente antecipadas em algumas microrregiões por indução estadual ou pela presença, na cultura local, de elementos favoráveis à cooperação (como é o caso da região Sul).

Os arranjos territoriais incluem: consórcios municipais; convênios; regiões integradas de desenvolvimento; regiões metropolitanas.

Embora as regiões integradas de desenvolvimento e a formação de regiões metropolitanas apresentem-se como opções para um enfrentamento conjunto dos problemas que extrapolam os limites e/ou as forças municipais, acredita-se que os convênios e, principalmente, os consórcios públicos sejam mecanismos de mais fácil aplicação. Isto porque para a realização desses, não se nota a presença dos obstáculos que acabam dificultando o funcionamento de outros arranjos, tais como a indefinição do que deve ser entendido como de "interesse metropolitano", ou mesmo outros dilemas ligados à autonomia municipal, que precisa ser compatibilizada com a obrigatoriedade de os Municípios aplicarem verbas próprias a determinados serviços e sob a forma definida pelo sistema de planejamento metropolitano. 
Com o advento da Lei oㅜ 11.107, de 6 de abril de 2005, os consórcios públicos passaram a contar com um marco legal próprio, o qual não apenas serviu para padronizar conceitos e procedimentos, mas também para deslindar controvérsias doutrinárias que geravam dúvidas e incertezas. Para completar o quadro, em 17 de janeiro de 2007, foi editado o Decreto ํo 6.017, o qual regulamentou o precitado diploma legal, estabelecendo normas detalhadas para a sua execução.

A referida lei preceitua que o consórcio será personalizado ( $\left(1^{\circ}\right.$, art. 1) e que tal personalidade jurídica poderá ser tanto de direito público, quando se tratar de associação pública, integrando, neste caso, a Administração Indireta de todos os entes da Federação consorciados (art. $6^{\circ}, \S 1^{\circ}$ ); quanto de direito privado, mediante o atendimento dos requisitos da legislação civil (art. 6은 II), nesse último caso a norma explicita que tal entidade privada observará normas de direito público no que concerne à celebração de contratos, licitação, prestação de contas e admissão de pessoal (art. $6^{\circ}$, $2^{\circ}$ ), o qual será regido, nesse particular, pela Consolidação das Leis do Trabalho (CLT).

Admite a transferência de pessoas quando a gestão associada assim exigir (inclusive também no que concerne a encargos e bens necessários à continuidade dos serviços transferidos), com a possibilidade de cessão de servidores ao consórcio, pelos entes consorciados ou pelos com ele conveniados, na forma da legislação de cada um, aclarando e dando concretude ao entendimento tradicional e dominante sobre esse tema, devendo o contrato de programa estabelecer, naquele particular, a quem caberá o ônus e os passivos do pessoal transferido.

A consorciação pode, por exemplo, promover desapropriações (inciso II, $\S 1^{\circ}$, art. $2^{\circ}$ ) e instituir servidões, nos termos de declaração de utilidade ou necessidade pública, ou ainda de interesse social, realizada pelo Poder Público. Tem, ainda, capacidade para emitir documentos de cobrança e para arrecadar tarifas e preços públicos pela prestação de serviços ou pelo uso ou outorga de bens públicos por eles administrados. Nesse sentido, a tradicional possibilidade de gerir serviços públicos comuns é especificada, ao se ressaltar que $o$ protocolo de intenções, ao fixar a autorização para a dita gestão 
associada, cuidará de explicitar, nos termos do inciso XI, art. $4^{\circ}$, da norma de regência: as competências transferidas ao consórcio público; os serviços públicos que serão geridos associadamente, inclusive no que concerne à delimitação de sua área territorial; a autorização para licitar ou outorgar concessão, permissão ou autorização de prestação de serviços; as condições pertinentes ao tema a serem obedecidas pelo contrato de programa; e, finalmente, os critérios técnicos para cálculo do valor das tarifas e de outros preços públicos, bem como para seu reajuste e revisão.

A pessoa jurídica resultante, formada pela consorciação poderá, ainda, representar os entes da Federação consorciados, perante outras esferas de governo, mas somente nos assuntos de interesse comum e em consonância com critérios que assim a autorizem, previstos no protocolo de intenções. Essa disposição deverá facilitar a cooperação intergovernamental com entes federados que não integrem a associação, pela instituição de um único portavoz para a temática compartilhada, reduzindo, desse modo, custos de transação. De fato, para intercâmbio de informações e experiências, bem como realização de tratativas, torna-se mais fácil procedê-las com um representante regional do que com cada integrante do consórcio. E no sentido de preservar ou manter o arranjo cooperativo, merece destaque a faculdade, a qualquer contratante adimplente com suas obrigações, de exigir o pleno cumprimento das cláusulas do contrato de consórcio público (inciso XII, art. $4^{\circ}$ ), abrindo oportunidade de tutela judicial do propósito de defender a manutenção do pacto original.

A Lei $n^{\circ} 11.107$, de 2005, fixa, ainda, as regras ordinatórias da formação e dissolução do pacto, assegurando-lhe uma estabilidade e permanência que se contrapõem ao caráter voluntário da associação. Preceitua, primeiro, a constituição por contrato (art. $3^{\circ}$ ), diferindo, portanto, do entendimento tradicional que aproximava a consorciação do convênio, figura esta que é tradicionalmente conceituada como aquela em que os interesses dos pactuantes não são opostos (como no contrato), mas coincidentes. Como requisito prévio, fixa-se o protocolo de intenções a ser firmado entre os entes da Federação interessados, o qual deverá ser ratificado mediante lei de cada 
integrante para que seja considerado celebrado o contrato de consórcio público. Dessa forma, vê-se solvida uma questão tormentosa, que era a da necessidade ou não de autorização legislativa, agora superada. $O$ ato formal, também é exigido para o desligamento de um consorciado ("retirada"), nos termos do art. 11 da lei de regência, devendo essa atuação ocorrer na assembléia geral, que é a instância máxima do consórcio (art. $4^{\circ}$, VII, da Lei ํㅜㄴ 11.107), na forma previamente disciplinada em lei.

Sobre o arcabouço contratual do consórcio, para além do próprio contrato de consórcio que o constitui, precedido de protocolo de intenções, ainda há que se dizer, que a norma geral instituiu a necessidade de contrato peculiar, nomeado contrato de programa, que regulará as obrigações entre os entes da Federação consorciados, ou destes com o consórcio, quando houver gestão associada de serviços públicos, nos termos do art. 13 da Lei de Consórcios Públicos.

Estipulou, ainda, um contrato de rateio, exigência do "caput" do art. $8^{\circ}$, para que sejam entregues recursos à consorciação. Seu propósito específico cinge-se ao de regular o modo de financiamento das atividades, sendo que o mesmo deverá, em regra, ser estabelecido por exercício financeiro, limitada sua vigência às dotações orçamentárias que o suportam. As obrigações nele previstas podem ter seu cumprimento exigido por qualquer um dos celebrantes, isoladamente ou em conjunto.

Não se pode deixar de mencionar, ainda, que a assembléia geral, instância máxima do consórcio, terá, no protocolo de intenções, a fixação do quorum para as suas deliberações, bem como do número de votos que cada ente da Federação possuirá na mesma, assegurando-se pelo menos um a cada ente consorciado. Vê-se que o legislador expressou a preocupação de instituir um órgão assemblear, com a representação de cada integrante da consorciação, garantindo que a vontade de cada participante contribuísse para a formação das deliberações coletivas.

Nesse particular, não se confunde essa instituição com a figura do representante legal, que deverá ser, obrigatoriamente, o Chefe do Poder 
Executivo de um dos entes federativos consorciados, eleito, nos termos das cláusulas que devem constar obrigatoriamente daquele protocolo, para um determinado mandato, nos termos do inciso VIII do art. 4ํ da norma de regência.

Finalmente, cumpre alguma referência ao caráter regional do instituto, cuja área territorial de atuação deve ser indicada no próprio protocolo de intenções, nos termos do art. $4^{\circ}$, III, da lei de regência. O precitado artigo, em seu $\S 1^{\circ}$, preceitua que a atuação do consórcio público, em termos geográficos, independentemente de figurar a União como consorciada, corresponderá à soma dos territórios municipais, quando contidos em um único Estado (e mesmo que este participe), ou estaduais, no caso de se constituir por mais de um ente federado estadual, incluindo-se, em um e em outro caso, a área do Distrito Federal, se este vier a integrar a consorciação.

Exclui-se, portanto, a possibilidade de consorciações contidas em uma única municipalidade, bem como de consórcios entre Municípios de Estados diferentes, em função do veto presidencial aos incisos III e V, do art. $4^{\circ}$.

Vale ressaltar que os consórcios mantêm o caráter voluntário, porquanto permanecem as municipalidades sem estarem compelidas a firmarem a cooperação, o que inclusive poderia ferir a autonomia municipal nos assuntos de interesse local, já que a Constituição de 1988, em seu art. 241, preceitua a existência de lei geral que autorize, e não que determine, a gestão associada de serviços públicos.

\section{Conclusões}

O fato de os Municípios terem sido elevados à condição de entes federados, com autonomia administrativa, política e financeira aumenta a responsabilidade destes entes perante a população local, principalmente no que diz respeito à prestação de serviços públicos. Entretanto, grande parte dos Municípios brasileiros não tem condições de gerar recursos próprios e, dessa forma, ficam totalmente dependentes das transferências de receitas constitucionais. 
Os resultados da pesquisa demonstraram que os municípios de grande porte, por possuírem pouca dependência dos recursos advindos das transferências municipais e alta arrecadação de tributos municipais possuem maiores possibilidades de desenvolvimento de uma política de gestão integrada de resíduos sólidos. Por outro lado, os municípios de pequeno porte não possuem recursos financeiros e nem administrativos para a consecução ampla dos objetivos previstos na Política Nacional de Resíduos Sólidos.

Parece claro que o objetivo central do federalismo cooperativo é evitar que as relações entre as três esferas de governo ocorram de forma isolada. $A$ experiência tem mostrado que a forma mais adequada para se conduzir as políticas públicas, principalmente aquelas voltadas para as áreas sociais, é a real cooperação entre os entes e coordenação entre os projetos, justamente 0 que falta na maior parte do país.

Assim, os consórcios administrativos apresentam-se como instrumentos de cooperação dos diversos entes da Administração Pública entre si e com particulares e inserem-se, assim, na ideia básica de conjugação de esforços comuns para realização de atividade de interesse público a que o empenho isolado dos envolvidos não faria possível.

\section{Referências bibliográficas:}

BARROS, Pedro Motta de. Consórcio Intermunicipal: ferramenta para o desenvolvimento regional. São Paulo: Alfa- Omega, 1995. 134 p.

BARROSO, Luis Roberto. Saneamento Básico: Competências constitucionais da União, Estados e Municípios. Revista Eletrônica de Direito Administrativo Econômico. Número 11, agosto/setembro e outubro de 2007. Salvador. Bahia, p. 3. Disponível em <http:॥ www.direitopublico.com.br>.

BRASIL. Lei o 12.305, de 02 de agosto de 2010. Institui a Política Nacional de Resíduos Sólidos; altera a Lei no 9.605, de 12 de fevereiro de 1998 e dá outras providências. Diário Oficial [da] República Federativa do Brasil, Poder Executivo, Brasília, DF, 03 ago. 2010. Seção 1. 
BRASIL. Ministério da Fazenda. Transferências Constitucionais: Estados e Municípios. Disponível

em: $<$ http://www3.tesouro.fazenda.gov.br/estados_municipios/transferencias_constit ucionais.asp>. Acesso em: 10 jun. 2013.

BRASIL. Projeto de Lei № 203/91. Dispõe sobre o acondicionamento, a coleta, o tratamento, o transporte e a destinação final dos resíduos de serviços de saúde. Disponível em: <http://www.camara.gov.br/proposicoesWeb/fichadetramitacao?idProposicao=1 5158>. Acesso em 13 jun 2013.

DA SILVA, José Afonso. Curso de Direito Constitucional Positivo. 27ํㅗㄹ ed. São Paulo: Malheiros Editores, 2006.

DALLARI, Dalmo de Abreu. Elementos da Teoria Geral do Estado. São Paulo: Saraiva, 2003.

DEMAJOROVIC, J. A evolução dos modelos de gestão de resíduos sólidos e seus instrumentos. Cadernos FUNDAP; 1996; 20:47-58. Disponível em: <http://www.gestaoambiental.ufscar.br/paginas/banco-de-teses-1/residuossolidos/gestao-de-residuos-solidos>. Acesso em 13 jun 2013.

DEMAJOROVIC, J.; BESEN, G. R.; RATHSAM, A. A. Os desafios da gestão compartilhada de resíduos sólidos face à lógica do mercado. In: JACOBI, P., FERREIRA, L. (Orgs.). Diálogos em Ambiente e Sociedade. São Paulo: Annablume, 2006. p 389-410.

MATTOS, Liana Portilho e SANTOS. Ângela Moulin Penalva. Emendas Constitucionais põem em cheque a autonomia municipal no Brasil. In:Município, Descentralização e Território. Rio de Janeiro: Forense, 2008.

SANTOS. Ângela Moulin Penalva. A Política Urbana nos Marcos do Federalismo Brasileiro. Artigo apresentado na ANPUR. 2009.

SANTOS. Ângela Moulin Penalva. Descentralização e Poder Municipal no Brasil. In:Município, Descentralização e Território. Rio de Janeiro: Forense, 2008. 
SOUZA, Celina. Desenho constitucional, instituições federativas e Relações intergovernamentais no Brasil pós-1988. In: Democracia, descentralização e desenvolvimento: Brasil e Espanha. Sonia Fleury (org). Rio de Janeiro: Editora FGV, 2006.

TRISTÃO, José Américo Martelli. A Administração tributária dos municípios brasileiros: uma avaliação do desempenho da arrecadação. Tese de Doutorado. São Paulo: FGV, 2003.

Data da submissão: 23 de setembro de 2013.

Data do aceite: 19 de dezembro de 2013. 